De Jans, S., Hudders, L., Herrewijn, L., Van Geit, K., \& Cauberghe, V. (2019). Serious games going beyond the Call of Duty: Impact of an advertising literacy mini-game platform on adolescents' motivational outcomes through user experiences and learning outcomes. Cyberpsychology: Journal of Psychosocial Research on Cyberspace, 13(2), article 3. http://dx.doi.org/10.5817/CP2019-2-3

\title{
Serious Games Going beyond the Call of Duty: Impact of an Advertising Literacy Mini-Game Platform on Adolescents' Motivational Outcomes through User Experiences and Learning Outcomes
}

\author{
Steffi De Jans ${ }^{1}$, Liselot Hudders' ${ }^{1,2}$, Laura Herrewijn ${ }^{1}$, Klara van Geit, \& Veroline Cauberghe ${ }^{1}$ \\ ${ }^{1}$ Department of Communication Sciences, Ghent University, Belgium \\ 2 Department of Marketing, Ghent University, Belgium
}

\begin{abstract}
As adolescents' advertising literacy is not yet fully developed with regard to non-traditional advertising, they should be made more resilient to this contemporary advertising. Therefore, the current study conducted a three-level, between-subjects experiment (advertising literacy intervention: control condition versus informational booklet versus serious mini-game platform) to examine the effectiveness of advertising literacy interventions among adolescents (aged ten to sixteen). The results showed that an advertising literacy intervention (compared to no intervention) increased Belgian adolescents' $\left(N=211, M_{\text {age }}=13.22\right)$ perceived dispositional advertising literacy, and subsequently, their motivation to critically reflect on advertising. In addition, the advertising literacy serious mini-game platform (compared to the informational booklet) increased the experience of flow among the adolescents, which in turn positively affected enjoyment, and perceived learning. Perceived learning then further increased adolescents' motivation to critically reflect on advertising and their motivation to interact with the learning materials.
\end{abstract}

Keywords: Advertising literacy intervention; adolescents; advertising literacy; serious mini-game platform; learning outcomes; motivational outcomes; user experiences

\section{Introduction}

Adolescents are an important target group for advertisers, as they not only have their own money to spend, but also have a huge impact on the purchase decisions of their parents and peers (Lapierre, Fleming-Milici, Rozendaal, McAlister, \& Castonguay, 2017). Adolescents tend to be early adopters, eager to try new products, and have brand preferences that are still subject to change (Lapowsky, 2014). Accordingly, advertisers are heavily targeting them with advertising. In 2019, total annual ad spending on kids is expected to grow to $\$ 4.2$ billion worldwide (Statista, 2019a). To break through the resulting advertising clutter, advertisers are furthermore trying to persuade adolescents and attract their attention with embedded advertising formats that 1 ) integrate the commercial content into the media content, 2) are fun and engaging, and 3) appeal to adolescents' personal preferences (Hudders et al., 2017). For instance, advertisers throw influencers into gear to promote their brands to adolescents, integrate their brands in popular music videos, digital games or television programs, and target adolescents with digital advertising based on their surfing behaviors. These embedded formats challenge adolescents' abilities to critically cope with and process advertising, which makes them subject to persuasion and may even lead to debts later in life (Baker \& George, 2010). The current study aims to examine how adolescents may be empowered to critically cope with advertising. 


\section{Adolescents' Advertising Literacy is Challenged in a Digital Environment}

Advertising literacy, defined as an individual's knowledge, abilities and skills to cope with advertising (Boush, Friestad, \& Rose, 1994), is needed to consciously and critically cope with advertising and avoid subconscious persuasion (Rozendaal, Lapierre, Van Reijmersdal, \& Buijzen, 2011). It consists of two facets: situational and dispositional advertising literacy (Hudders et al., 2017). When exposed to an advertisement, individuals should recognize the persuasive attempt as advertising in order for them to critically reflect on it. These skills have been defined as situational advertising literacy (Hudders et al., 2017). Dispositional advertising literacy refers to all knowledge and skills one possesses regarding persuasion in advertising context (Hudders et al., 2017, p. 335). An extensive dispositional advertising literacy guides and eases the critical reflection and enables the application of a more successful coping strategy (Fransen, Verlegh, Kirmani, \& Smit, 2015). Hence, dispositional advertising literacy needs to be activated to make a critical reflection on a persuasive attempt possible. Dispositional advertising literacy develops according to age and experience with advertising (Boush et al., 1994; Friestad \& Wright, 1994). Therefore, it can be expected that adolescents' dispositional advertising literacy is not yet fully developed, especially when it comes to embedded advertising. Previous research has shown that adolescents believe that they can recognize advertising fairly well and have a good understanding of it (De Jans, Hudders, \& Cauberghe, 2018). In practice, however, they have more difficulties activating advertising literacy for embedded advertising compared to traditional advertising (Verhellen, Oates, De Pelsmacker, \& Dens, 2014), and their advertising literacy for embedded advertising formats (specifically for targeted ads) only matures at the age of 16 (Zarouali et al., 2018).

\section{Digital Game-Based Learning to Empower Adolescents}

Consequently, some authors have suggested that minors should be empowered to critically cope with and process advertising messages through interventions and educational programs that enhance their advertising literacy (Austin \& Johnson, 1997; Eagle, 2007). Most previous research has attempted to do this by examining the potential impact of a traditional learning approach such as a traditional lesson or an instructional video on children's advertising literacy and advertising effects (De Jans, Hudders, \& Cauberghe, 2017; Hudders, Cauberghe, \& Panic, 2016; Nelson, 2016). However, adolescents are often bored with and disengaged from the traditional learning process, which may negatively affect the traditional learning program's effectiveness. It is therefore assumed that digital game-based learning (DGBL) might counter this and be an appropriate method to educate adolescents about advertising.

DGBL refers to a learning method that merges the content of learning with the entertaining power of digital games to use it as an educational tool (Prensky, 2003). The game-based learning market is expected to increase from $\$ 3.5$ billion in 2018 to $\$ 17$ billion in 2023 worldwide (Statista, 2019b). In addition, gaming plays a central role in the daily lives of adolescents (Ofcom, 2017). The current study, therefore, examines whether serious games can positively affect learning outcomes related to advertising literacy (e.g. perceived learning) and subsequently motivational outcomes (e.g. motivation to critically reflect on advertising). Serious games are tools for DGBL and are defined as games that are used for more than just mere entertainment (Susi, Johannesson, \& Backlund, 2007). The goal of serious games is twofold: they have to be fun and entertaining and they have to be educational (Bellotti, Kapralos, Lee, Moreno-Ger, \& Berta, 2013). Serious games can activate intense user experiences among adolescents such as flow and enjoyment (Admiraal, Huizenga, Akkerman, \& Ten Dam, 2011; Hamari et al., 2016), which may subsequently enhance learning outcomes and motivation (Brom, Preuss, \& Klement, 2011; Ke \& Grabowski, 2007; Papastergiou, 2009; Qian \& Clark, 2016; Rosas et al., 2003). Hence, user experiences such as flow and enjoyment seem crucial mediators in the investigation of DGBL.

\section{The Scope and Added Value of the Current Study}

Despite these promising results, the educational value of conventional serious games has been questioned because they often require a significant amount of players' time, cover too many learning subjects at once, and have complicated evaluation processes and high developmental costs (Illanas, Gallego, Satorre, \& Llorens, 2008; Juul, 2010; Trefry, 2010). Therefore, the current study examines the impact of a serious mini-game platform: a platform that consists of short games that each focus on a specific concept or learning goal related to a learning topic (Frazer, Argles, \& Wills, 2007; Illanas et al., 2008; Smith \& Sanchez, 2010). 
The current study is also innovative as it focuses on adolescents. This target group has been largely ignored in past research on interventions (for an exception see Adams, Schellens, and Valcke, 2017). This may be partly explained by regulation and public policy primarily focusing on children younger than twelve years old, as the age of 12 is often used as a threshold to deem it fair to target minors with advertising (Nairn, 2014). Advertising targeting adolescents, however, is not specifically regulated. Additionally, most studies so far examine how situational advertising literacy can be improved by interventions. Interventions may be especially designed to improve dispositional advertising literacy (Hudders et al., 2017), as these interventions may further develop adolescents' associative network related to advertising, which they can address when they are exposed to any specific (embedded) advertising attempt.

Finally, while most previous studies on DGBL examined the impact on actual knowledge acquisition (e.g. Papastergiou, 2009; Sung \& Hwang, 2013), this study extends prior research on the effectiveness of DGBL by investigating both learning and motivational outcomes. In particular, and with regard to learning outcomes, the current study explores the knowledge adolescents perceive to have gained about advertising from the intervention (i.e. perceived learning) and the knowledge adolescents perceive to possess about different advertising formats (i.e. perceived dispositional advertising literacy). As a single exposure to the interventions will likely not be sufficient to achieve a great improvement in adolescents' learning outcomes, two motivational outcomes are also assessed, namely: adolescents' motivation to critically reflect on advertising and their motivation to interact with the learning materials.

\section{The Aims of the Current Study}

To conclude, the goal of the current study is threefold. First, the article examines the effectiveness of advertising literacy interventions (serious mini-game platform and informational booklet on advertising literacy) compared to no intervention on adolescents' (10-16 years) perceived dispositional advertising literacy and their motivation to critically reflect on advertising. Second, the effects of an advertising literacy serious mini-game platform (compared to an informational booklet) on user experiences (i.e. flow and enjoyment) are examined. Third, this study investigates how these user experiences affect adolescents' learning (i.e. perceived learning and perceived dispositional advertising literacy), and further motivational outcomes (i.e. motivation to critically reflect on advertising and motivation to interact with the learning materials).

\section{Conceptual Background an Hypotheses Development}

In the first part of the theoretical framework, we compare an advertising literacy intervention with no intervention (control condition) with regard to one learning outcome (i.e. perceived dispositional advertising literacy) and one motivational outcome (i.e. motivation to critically reflect on advertising). This is because the other variables in our research, namely the user experiences, perceived learning and motivation to interact with the learning materials, are specifically tied to the intervention (i.e. the booklet or the game platform). Accordingly, these variables only become relevant in the second part of the paper, that focuses on the specific differences between the two interventions. See Figure 1 for the conceptual model that we used to test the general effectiveness of an intervention (compared to no intervention) in increasing motivation to critically reflect on advertising through perceived dispositional advertising literacy.

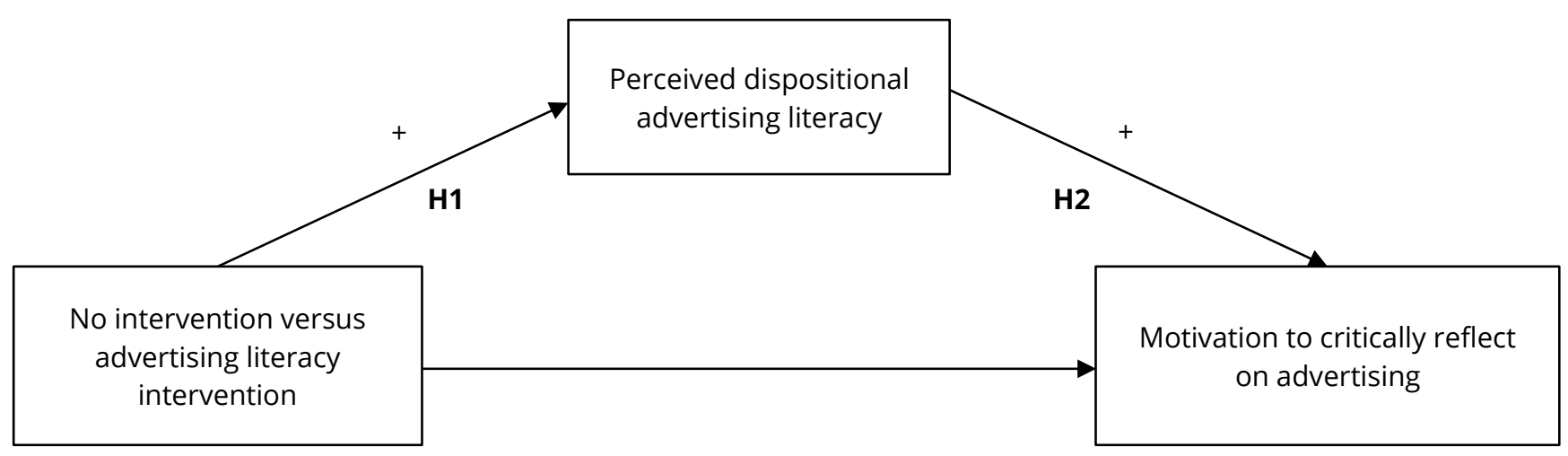

Figure 1. Conceptual model: no intervention versus advertising literacy intervention. 
The second part of the theoretical framework focuses on the comparison of the two different advertising literacy interventions: a traditional learning approach (i.e. an informational booklet) and a DGBL approach (i.e. a serious mini-game platform). These learning approaches are compared with regard to user experiences (i.e. flow and enjoyment), learning outcomes (i.e. perceived learning and perceived dispositional advertising literacy) and motivational outcomes (i.e. motivation to critically reflect on advertising and motivation to interact with the learning materials). See Figure 2 for a visualization of the hypotheses (informational booklet versus serious minigame platform).

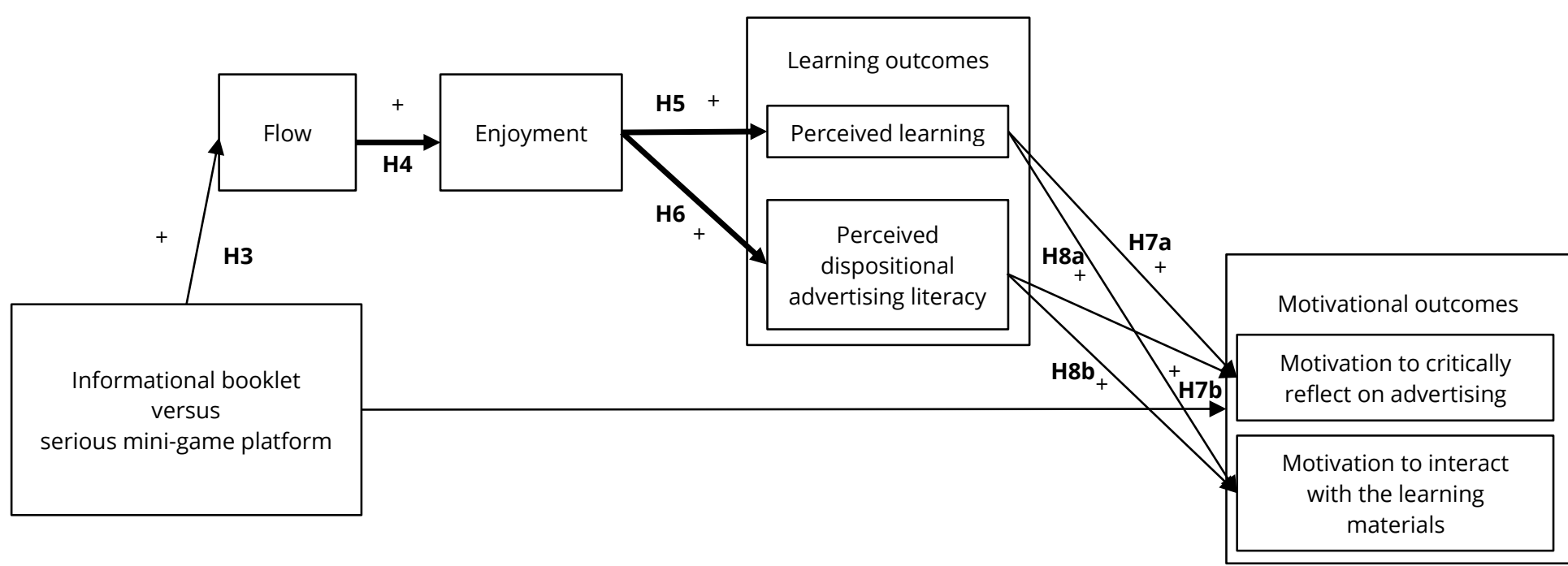

Figure 2. Conceptual model: informational booklet versus serious mini-game platform.

\section{Interventions to Enhance Adolescents' Advertising Literacy}

Dispositional advertising literacy develops throughout our life span. Its development is based on experience with advertising, consumer socialization influences, and the development of cognitive and emotional skills (Friestad \& Wright, 1994; John, 1999). Despite the general assumption that adolescents possess an adult-level of advertising literacy for traditional advertising at the age of twelve, they may still have difficulties to cope with embedded advertising (Verhellen et al., 2014). This is due to the fun, engaging and hidden nature of these advertising formats, which makes it more difficult to recognize these formats as advertising, understand them and critically reflect on them.

Additionally, dispositional advertising literacy develops and expands with each experience that adolescents have with an advertising attempt (John, 1999). This implies that consumers have less difficulties to understand advertising they are often exposed to. However, the current advertising landscape is constantly evolving and adolescents are more than ever exposed to new advertising formats. Accordingly, their dispositional advertising literacy is continuously challenged, as this new information needs to be added to their associative network. To conclude, adolescents' cognitive and emotional capabilities are still developing, which may hinder a full understanding of and proper coping with embedded advertising (Boush et al., 1994; Friestad \& Wright, 1994; Vanwesenbeeck et al., 2016; Zarouali et al., 2018). Interventions that may expand adolescents' dispositional advertising literacy are therefore indispensable (Hudders et al., 2017).

Previous research has shown that advertising literacy interventions are effective in enhancing children's situational advertising literacy and, subsequently, mitigating advertising effects. Most of these studies have investigated the effectiveness of a traditional advertising literacy learning approach in the form of a traditional lesson about advertising in a classroom setting (using PowerPoint materials and/or a dialogue) that aims to enhance children's recognition and understanding of advertising. The length of these traditional training sessions usually varies from ten minutes to three hours. These studies have shown that such interventions can be effective in enhancing 
children's recognition and understanding of advertising for both traditional and embedded advertising formats (De Jans, Hudders, et al., 2017; Donohue, Henke, \& Meyer, 1983; Hudders et al., 2016; Nelson, 2016; Wollslager, 2009). An, Jin, and Park (2014) also examined the impact of an advertising literacy serious game (an educational game aimed at helping children understand the persuasive intent of online advergames) by comparing it with a control condition (a serious game about science that was unrelated to advertising). The results indicated that children were better able to recognize an advergame as advertising when they were first exposed to the advertising literacy serious game (compared to the science game). To the authors' knowledge, only one study examined the impact of an advertising literacy intervention among adolescents. In particular, the study showed that a one-hour intervention on moral advertising literacy (i.e. moral judgement of advertising formats, tactics and messages) increased adolescents' (between fourteen and eighteen years) knowledge about advertising law (Adams et al., 2017).

Both interventions examined in this study (a serious mini-game platform and an informational booklet) are designed to improve adolescents' knowledge of different advertising tactics and strategies advertisers use to persuade adolescents. Hence, the aim of the interventions is to extend adolescents' dispositional advertising literacy. This is important so adolescents are able to critically reflect on advertising when exposed to it. Accordingly, the perception of adolescents about how much they know about the tactics and strategies used by advertisers is an important indicator for the effectiveness of the interventions. Therefore, the current study focuses on perceived dispositional advertising literacy, whereas most previous studies that examined the effectiveness of an advertising literacy intervention among children, as indicated above, measured situational advertising literacy. Based on the results of these previous studies, the fact that the interventions were specifically designed to enhance dispositional advertising literacy, and the assumption that dispositional advertising literacy develops through experience with advertising, consumer socialization and the development of cognitive and emotional capabilities (Friestad \& Wright, 1994; John, 1999), we expect that adolescents' perceived dispositional advertising literacy will be higher after exposure to an advertising literacy intervention.

H1: Adolescents' perceived dispositional advertising literacy will be higher after exposure to an advertising literacy intervention (serious mini-game platform and informational booklet) compared to no intervention.

In addition, an intervention in the form of an advertising literacy video (an instructional film for children aimed at enhancing their recognition of commercials and their understanding of advertising's commercial intentions) has been shown to also increase children's skeptical attitude toward advertising (Brucks, Armstrong, \& Goldberg, 1988; Roberts, Christenson, Gibson, Mooser, \& Goldberg, 1980). As an activation of dispositional advertising literacy is needed to make a critical reflection on advertising possible, we expect that an advertising literacy intervention will enhance adolescents' motivation to critically reflect on advertising through an increased perceived dispositional advertising literacy. This is because the adolescents will be informed about (embedded) advertising through the advertising literacy intervention and will therefore believe to be able to recognize and understand different advertising formats and tactics (e.g. Hudders et al., 2016; Nelson, 2016). Additionally, adolescents will discover the hidden nature of embedded advertising and they will understand the emotions and impulses that embedded advertising arouses, which will trigger their skeptical attitudes and their motivation to critically reflect on advertising.

H2: An advertising literacy intervention (compared to no intervention) will enhance adolescents' motivation to critically reflect on advertising through an increased perceived dispositional advertising literacy.

\section{The Effects of an Advertising Literacy Serious Mini-game Platform versus a Traditional Intervention}

The current study specifically focuses on an advertising literacy intervention that makes use of DGBL, specifically a serious game, to teach adolescents about advertising (literacy). Serious games are defined as "any form of interactive computer-based game software for one or multiple players to be used on any platform and that has been developed with the intention to be more than entertainment" (Ritterfeld, Cody, \& Vorderer, 2009, p. 6). Although the popularity of regular serious games continues to rise and studies provide evidence for their effectiveness in terms of user experiences, learning outcomes and motivation among adolescents (Admiraal et al., 2011; Brom et al., 2011; Hamari et al., 2016; Ke \& Grabowski, 2007; Qian \& Clark, 2016), the educational value and effectiveness of such games can be questioned. Many serious games are complicated games that require different 
skills and are hard to learn. For example, they can have very complex interfaces and controls that allow a large number of actions within the game space. Hence, these conventional serious games are very demanding, often require a certain degree of prior digital game experience, and require many hours of practice to master the rules and scenario conditions (Juul, 2010; Trefry, 2010). Furthermore, these serious games mostly cover a wide range of educational content and therefore lose concreteness and complicate the evaluation of the educational progress of the players (Illanas et al., 2008).

Recently, a new form of serious games was introduced as an alternative to the conventional serious games, namely serious mini-games or conceptual mini-games (Illanas et al., 2008). A serious mini-game is a short game that focuses on a single learning goal or concept. Serious mini-games consist of basic game mechanics that make it easy for players to reach a high level of proficiency within a short period of time (Trefry, 2010). Players do not lose time learning how to play the serious mini-game and can immediately focus on the central learning goal Jonker, Wijers, \& Van Galen, 2009; Smith \& Sanchez, 2010). In addition, the games only require little time from the players so they easily fit within the scope of a class period and can be played repeatedly (Illanas et al., 2008; Prensky, 2008; Smith \& Sanchez, 2010). Furthermore, the rules remain unchanged throughout the game, which makes it easy to evaluate students' educational progress (Illanas et al., 2008). Finally, the developmental cost of mini-games is much lower compared to conventional serious games (an estimate of $\$ 17.000$ compared to an amount of 10 to 300 thousand dollars for conventional serious games (De Jans, Van Geit, Cauberghe, Hudders, \& De Veirman, 2017; Marfisi-Schottman, George, \& Tarpin-Bernard, 2010).

Some studies advocate the pedagogical and practical value of these serious mini-games in educational settings (Frazer et al., 2007; Illanas et al., 2008; Jonker et al., 2009; Smith \& Sanchez, 2010). Other authors, however, believe that a serious mini-game is too shallow and small to provide any real educational value (Frazer et al., 2007; Prensky, 2005). In the current study, a solution was sought by combining several serious mini-games into a serious minigame platform (Frazer et al., 2007; Smith \& Sanchez, 2010). More specifically, this study examines a serious minigame platform, developed by De Jans, Van Geit, et al. (2017), that consists of different serious mini-games that each focus on a single and specific learning goal of advertising literacy. Hence, each mini-game represents a didactic unit that explores the learning topic from different angles (Illanas et al., 2008). This serious mini-game platform was designed using informant design, which means that different stakeholders were involved at different stages of the design process depending on their expertise (Scaife, Rogers, Aldrich, \& Davies, 1997). To the authors' knowledge, no studies have yet been conducted to provide evidence for the effectiveness of serious mini-games or a serious mini-game platform. Therefore, this study examines the effectiveness of an advertising literacy serious mini-game platform on user experiences, learning outcomes and motivational outcomes by comparing it with a more traditional intervention (namely an informational booklet).

\section{User Experiences}

Regardless of the type of game, its most important aspect is that players experience a state of flow during game play. Flow refers to a state of intense concentration or absolute absorption in an activity in which "thoughts, intentions, feelings, and all of the senses are focused on the same goal" (Csikszentmihalyi, 1990, p. 41). Csikszentmihalyi's (1990) flow theory suggests that flow results from a balanced and symbiotic relationship between challenges and the skills needed to meet those challenges. In the context of DGBL, it is therefore important that the game's challenges closely meet the player's skills: a player's skills can neither be overmatched nor underutilized to meet a challenge (Admiraal et al., 2011). When players are in a state of flow, they are solely focused on that activity and their sense of time is distorted (Hwang, Wu, \& Chen, 2012).

Previous studies have shown that serious games can be effective in promoting the flow experience among minors. Admiraal et al. (2011) conducted a study among adolescents (twelve to sixteen years) to examine the effectiveness of a game about medieval Amsterdam merging digital and urban play spaces. The study demonstrated that the adolescents were in a state of flow while playing the game, although they were distracted by several factors (e.g. navigation). In addition, Hwang et al. (2012) found that an online serious game significantly promoted the flow experience among elementary school children. Finally, using two serious games, Hamari et al. (2016) showed that DGBL effectively engaged high school students in the learning activity, demonstrated by increased levels of challenges and skills during game play. 
Based on flow theory (Csikszentmihalyi, 1990), we expect that the adolescents will experience more flow while playing the serious mini-game platform compared to reading the informational booklet. This may be due to the interactive and immersive characteristics of the serious mini-games, and because the serious mini-games are especially designed to offer the players challenges that meet their skills and that they have to overcome.

H3: A serious mini-game platform will evoke a greater experience of flow among adolescents compared to an informational booklet.

Enjoyment is considered the core experience of media entertainment and can be defined as the sum of positive reactions toward media experiences including physiological, affective, and cognitive dimensions (Barzilai \& Blau, 2014; Ritterfeld \& Weber, 2006; Vorderer, Klimmt, \& Ritterfeld, 2004). Previous research on DGBL has shown that flow can be a significant predictor of enjoyment. In particular, flow positively affects feelings of enjoyment and satisfaction (Admiraal et al., 2011; Barzilai \& Blau, 2014; Hamari et al., 2016; Kristian Kiili, 2005). Hence, enjoyment is considered a consequence of flow (Hoffman \& Novak, 2009; Kristian Kiili, 2005). We therefore expect that the evoked experience of flow while playing the set of serious mini-games will positively affect adolescents' feeling of enjoyment during the experience.

H4: The enhanced experience of flow while playing the serious mini-game platform (compared to reading the informational booklet) will positively affect adolescents' feeling of enjoyment.

\section{How the User Experiences of Flow and Enjoyment Affect Learning and Motivational Outcomes}

Learning outcomes. Perceived learning is defined as "the set of beliefs and feelings one has regarding the learning that has occurred" (Caspi \& Blau, 2008, p. 327). It is a retrospective evaluation of the learning experience (Barzilai \& Blau, 2014; Caspi \& Blau, 2008). Thus, perceived learning differs from actual learning, as it refers to the learner's sense that knowledge is acquired regardless of whether that knowledge was actually acquired (Barzilai \& Blau, 2014; Caspi \& Blau, 2008). Barzilai and Blau (2014) stressed the importance of measuring perceived learning in the context of DGBL, as self-assessment of the learning process and acquisition of knowledge (which involves metacognitive monitoring and evaluation) might have an impact on the players' behavior by encouraging them to play the game again.

Barzilai and Blau (2014) found that flow, enjoyment, and perceived learning were strongly correlated and that flow significantly predicted both enjoyment and perceived learning. In their study, Hamari et al. (2016) showed that the experience of flow resulted in more engagement in the game (composed of enjoyment, interest and concentration in their study), which then enhanced perceived learning among adolescents. Hence, user experiences and learning experiences are strongly intertwined aspects of DGBL (Barzilai \& Blau, 2014; Hamari et al., 2016; Ritterfeld \& Weber, 2006). Based on these insights, we expect that the serious mini-game platform (compared to the informational booklet) will result in a higher level of perceived learning among adolescents via the user experiences of flow and enjoyment.

H5: A serious mini-game platform will enhance adolescents' perceived learning on advertising literacy (compared to an informational booklet) through enhanced experiences of flow and further enjoyment.

Some studies have provided evidence for the effectiveness of DGBL on adolescents' cognitive learning outcomes. For example, Papastergiou (2009) showed that adolescents' (sixteen to seventeen years) knowledge of computer memory concepts was higher after a DGBL approach (compared to a similar application in the form of a website). In addition, a DGBL approach also showed to be effective in facilitating students' $21^{\text {st }}$ century skill development (including their critical thinking skills) (Qian \& Clark, 2016). In contrast, although adolescents (14-18 years) showed a higher level of engagement in instructions and learning activities while playing a serious game on genetics, Annetta, Minogue, Holmes and Cheng (2009) concluded that the adolescents did not demonstrate a greater conceptual knowledge and did thus not show more effective learning compared to the non-playing (control) group.

Hence, a DGBL approach does not necessarily have a direct positive impact on (perceived) learning outcomes among adolescents in the short run. It is therefore assumed that DGBL may affect learning achievements through the experiences of flow and enjoyment. Previous research has provided evidence for the positive impact of the 
state of flow on learning. Kiili (2005) indicated that the experience of flow within a serious game positively affected learning. In addition, Hou (2015) found, in the context of a role-playing simulation game, that more flow resulted in more complete and prominent reflective behavioral patterns among students. In line with these studies, Brom et al. (2014) concluded that the experience of flow was positively related to positive affect (i.e. mood) among adolescents, and that both flow and positive affect were positively related to learning. However, other studies could not find this direct positive impact of flow on learning outcomes. For example, Admiraal et al. (2011) showed that flow had an impact on adolescents' game performance, but not on their learning outcome. Therefore, we expect that flow (activated by a serious mini-game platform) will affect adolescents' confidence in their knowledge on different advertising formats through the experience of enjoyment. Enjoyment, which is perceived as a consequence of flow, has generally been found to be positively related to learning outcomes (Pekrun, Goetz, Frenzel, Barchfeld, \& Perry, 2011; Pekrun, Goetz, Titz, \& Perry, 2002).

H6: A serious mini-game platform will enhance adolescents' perceived dispositional advertising literacy (compared to an informational booklet) through enhanced experiences of flow and further enjoyment.

Motivational outcomes. The success of all online games depends on players' motivation to return to the game and interact with it again. Hence, players' intention to interact with online games again in the future is assumed to be a crucial factor in the existence of those games, as customer return is an important aim in all industries (Pine, Peppers, \& Rogers, 2009; Refiana, Mizerski, \& Murphy, 2005). It is assumed that the experiences of flow and enjoyment are crucial in this process. When players have mastered specific challenges, they develop a greater level of skills. Then, they are confronted with more complex challenges and again have to improve their skills. Players will thus feel like they have gained skills and knowledge about the topic as they go along in the game. Due to these characteristics, serious games are assumed to positively influence intrinsic motivation (Wouters, Van Nimwegen, Van Oostendorp, \& Van Der Spek, 2013). Whereas adolescents are generally extrinsically motivated (due to outside pressures such as parents) to interact with traditional learning materials, serious games might intrinsically motivate adolescents to learn (Papastergiou, 2009; Prensky, 2003). Adolescents will be motivated to interact with the learning materials again due to the interplay between challenges and skills, the fun and entertaining nature of serious games, and eventually their belief in their acquired skills and knowledge about the topic.

In addition, if players do not feel that they have learned about the learning topic from the learning platform, it is very unlikely that they will be motivated to use their acquired knowledge and interact with the learning materials again. This may be explained by social cognitive theory, which suggests that future behavior can be predicted by past experiences (Bandura, 1986). When a certain experience was seen as positive, a person will be more inclined to do it again. In contrast, when an experience was negative, an individual will be less inclined to repeat it. Thus, the expectations one has with regard to the outcomes of a specific experience affect the willingness to invest effort in it.

Hence, based on social cognitive theory, we expect that when adolescents have a positive experience with a learning platform, feel that they have learned from the learning platform and gained knowledge about the learning topic, they will be more intrinsically motivated to interact with the learning materials again and use their knowledge when they are confronted with it (i.e. critical reflection on advertising), whereas adolescents are often extrinsically motivated to interact with traditional learning approaches.

H7: A serious mini-game platform will enhance adolescents' a) motivation to critically reflect on advertising and b) motivation to interact with the learning materials (compared to an informational booklet) through the enhanced, consecutive experiences of flow, enjoyment and perceived learning.

H8: A serious mini-game platform will enhance adolescents' a) motivation to critically reflect on advertising and b) motivation to interact with the learning materials (compared to an informational booklet) through the enhanced, consecutive experiences of flow, enjoyment and perceived dispositional advertising literacy. 


\section{Method}

\section{Design and Procedure}

A three-level, between-subjects experimental study (advertising literacy intervention: control condition versus informational booklet versus serious mini-game platform) was conducted among adolescents. The control group completed a 20-minute regular course, which was unrelated to advertising, given to the adolescents by their usual teacher. A second group of adolescents read an informational booklet about advertising for 20 minutes, and a third group played a set of serious mini-games on advertising literacy on a computer (also for 20 minutes). After completing the regular course, reading the booklet, or playing the set of serious mini-games, the adolescents were instructed to complete a questionnaire. The participants were randomly allocated to one of the three conditions at a class level, which means that all students within the same class were assigned to the same condition. To each experimental condition, at least two classes from different schools were allocated. The experimental and control groups did not differ with respect to gender $\left(\chi^{2}(2)=5.84, p=.054\right)$ or age $(F(2,210)=.28, p=.754)$. To ensure no interaction between the participants, they were asked to complete the questionnaire individually. A researcher was always present to guide the experiment.

\section{Stimulus Material}

For the advertising literacy serious mini-game platform condition, a game platform consisting of four mini-games was used. This advertising literacy game platform was developed using informant design (De Jans, Van Geit, et al., 2017). The informant design framework refers to a design method that involves different stakeholders at different stages of the design process, depending on their expertise (Scaife et al., 1997). This design method maximizes the value of each stakeholder's contributions. Hence, in the design process of the serious mini-game platform different relevant stakeholders were involved: industry experts, academic experts, pedagogical experts, game developers, and end users (adolescents between the age of twelve and eighteen years). The serious mini-games were developed to enhance adolescents' advertising literacy and their critical reflection on advertising. The advertising literacy game platform is designed as follows. When a player visits the game platform, he/she can choose between four different avatars (two girls and two boys) and name his/her character. After choosing and naming the avatar, the player is able to play four serious mini-games that can be played in a random order. Each game focuses on a different aspect of advertising literacy: the 'Count the Ads' game aims to increase the player's recognition of advertising; the 'Skate Game' aims to show how in-game advertisements can influence a player's product choice and also focuses on ad recognition; the 'Profile Crush' game confronts its players with personal data collection practices by requesting the players to connect with their Facebook account before they can play the game; and the 'Quiz' game tests the general level of advertising literacy of the player. Throughout the serious mini-games, the players also receive information about advertising practices used by advertisers to influence consumers. See De Jans, Van Geit, et al. (2017) for more detailed information on how the serious mini-game platform was developed. See Figure 3 for a screenshot of the serious mini-game platform.

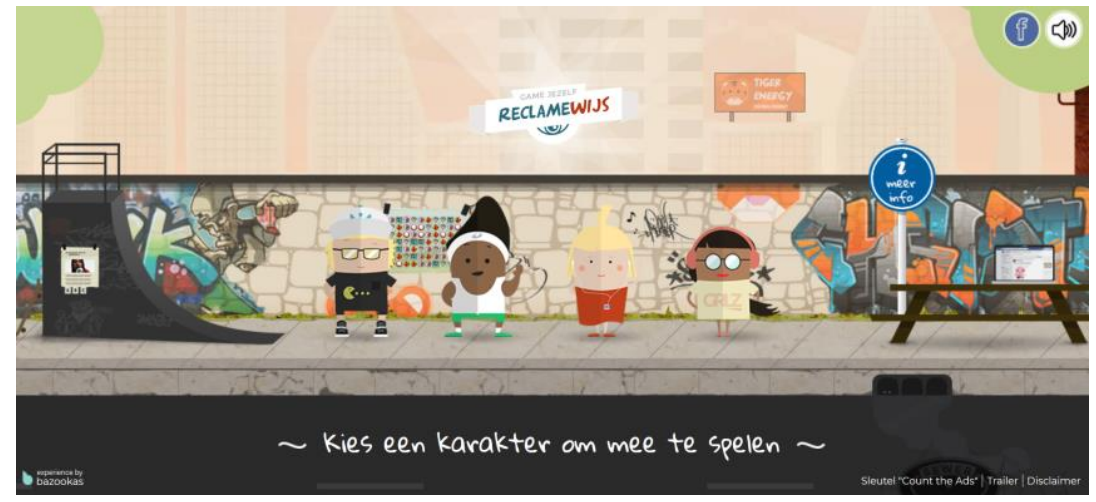

Figure 3. Screenshot of the serious mini-game platform (text in the screenshot is Dutch for 'Choose a character to play with'). 
For the advertising literacy booklet condition, an informational booklet about advertising and advertising literacy was developed by the authors. This booklet, which consists of 18 pages, was developed based on the content and design of the game platform and contained the same information (see Appendix 1 for the informational booklet). The avatars, images and graphics of the game world were also used in the booklet to ensure the same graphical lay-out in both experimental conditions. For example, similar to the game platform where the avatars were first introduced and the players had to choose one before they could play the games, the first page of the booklet also introduced the avatars from the game platform. Also similar to the game platform, the booklet mainly focused on advertising recognition, awareness of advertising tactics and awareness of personal data collection. In addition, the information and feedback that was given to the players in the mini-games was also incorporated in the informational booklet. For example, the information that was given and the questions that were asked to the players in the last mini-game (the 'Quiz' game), were also incorporated into the booklet as questions or statements the reader could think about. The exercises (including feedback) from the 'Count the Ads' game were also incorporated in the informational booklet. Hence, the booklet and the game platform were very similar, and only differed in terms of the gaming aspect. See Figure 4 for the cover sheet of the informational booklet.

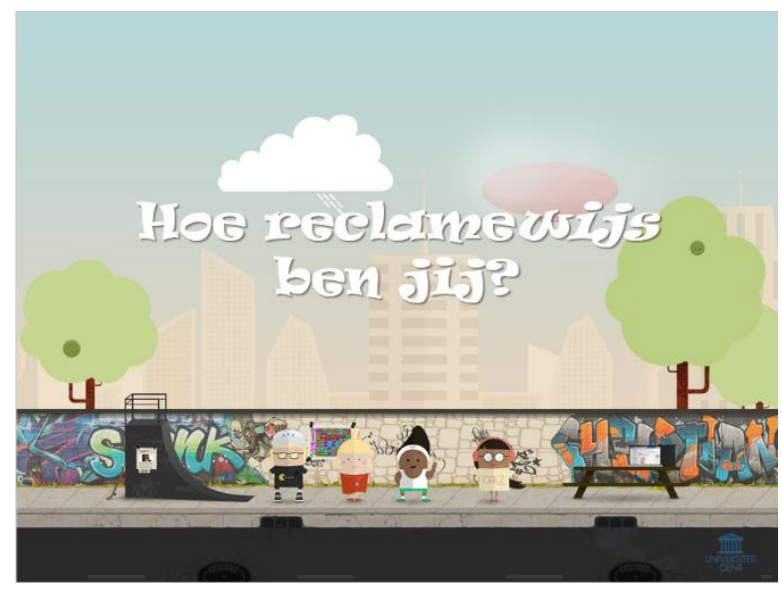

Figure 4. Cover sheet of the informational booklet (text in the screenshot is Dutch for 'How advertising literate are you?').

\section{Participants}

In total, 211 adolescents between 10 and 16 years $\left(M_{\text {age }}=13.22, S D=1.83\right)$ participated in the study, of which 117 were girls (55.5\%). The adolescents were recruited from four different schools (one primary school and three secondary schools) in Belgium. A convenience sample of schools was contacted for the study, and the experiment was conducted in those schools that were willing to participate. Approval was obtained from the ethical review board of the faculty, from the schools and teachers involved, and adolescents' consent was requested before they could participate in the study.

\section{Measures}

Flow. Flow was measured using three items from the scale of Barzilai and Blau (2014): "I lost track of time when I read the booklet/played the games," "When I read the booklet/played the games I did not think of anything else," and "I was totally immersed in the booklet/games." These items were answered on a five-point Likert-type scale ranging from "totally disagree" to "totally agree" ( $\alpha=.78 ; M=2.97, S D=1.07)$.

Enjoyment. Enjoyment was gauged using six items, adapted from Barzilai and Blau (2014), on a five-point Likerttype scale from "totally disagree" to "totally agree": "I enjoyed the booklet/games," "I had fun reading the booklet/playing the games," "I enjoyed learning about advertising from the booklet/games," "I liked the booklet/games," "I liked the characters in the booklet/games," and "I was bored while reading the booklet/playing the games" ( $a=.78, M=3.45, S D=0.80$ ). The last item was recoded before the construct was computed. 
Perceived learning. Perceived learning was assessed by measuring four items adapted from Barzilai and Blau (2014): "The booklet/games will help me recognize advertising better," "I learned new things about advertising from the booklet/games," "The booklet/games will help me remember the things I learned about advertising when I see advertising," and "The booklet/games made me want to learn more about advertising and advertising literacy" $(a=.83, M=2.87, S D=0.95$ ). These items were gauged on a five-point Likert-type scale ranging from "totally disagree" to "totally agree."

Perceived dispositional advertising literacy. Eight items were used to measure perceived dispositional advertising literacy. In particular, the adolescents had to answer the question "I know a lot about this advertising format" for eight different advertising formats: television commercials, product placement, online banners, sponsored blogs, advergames, cookies, YouTube advertising and Facebook advertising. These items were gauged on a five-point Likert-type scale from "totally disagree" to "totally agree" ( $a=.78, M=2.89, S D=0.83)$.

Motivation to critically reflect on advertising. To measure adolescents' motivation to critically reflect on advertising, four items (adapted from Rozendaal, Opree and Buijzen, 2016) on a five-point Likert-type scale from "totally disagree" to "totally agree" were used ( $\alpha=.76, M=2.51, S D=0.95)$ : "If I see advertising in the future, I will think carefully about its purpose," "If I see advertising in the future, I will think critically about the content of the advertising message," "If I see advertising in the future, I will check whether the advertisement tells the truth," and "If a see a brand in the future, I will always consider whether it is advertising."

Motivation to interact with the learning materials. We measured motivation to interact with the learning materials using three items: "I will read the booklet/play the games in the future," "I will recommend the booklet/the games to my friends," and "After reading the booklet/playing the games, I would like to talk about advertising literacy with my parents or friends." These items were measured on a five-point Likert-type scale from "totally disagree" to "totally agree" ( $\alpha=.84, M=2.40, S D=1.01)$.

These six constructs were measured in both the serious mini-game platform condition and the informational booklet condition. In the control condition, only adolescents' perceived dispositional advertising literacy and their motivation to critically reflect on advertising were measured. It was not possible to measure the other constructs in the control condition, as these specifically refer to an intervention.

\section{Results}

\section{Covariate}

Age was included as a covariate in all the analyses, as it significantly predicted enjoyment $\left(R^{2}=.05, F(1,130)=6.49\right.$, $p=.012)$, perceived learning $\left(R^{2}=.06, F(1,129)=6.39, p=.007\right)$, perceived dispositional advertising literacy $\left(R^{2}=\right.$ $.07, F(1,191)=13.56, p<.001)$ and motivation to interact with the learning materials $\left(R^{2}=.17, F(1,129)=27.22, p\right.$ $<.001)$. Enjoyment, perceived learning and motivation to interact with the learning materials decrease with age, while perceived dispositional advertising literacy increases with age.

\section{Correlations}

Before testing the proposed hypotheses, it was investigated how the different constructs were related. Flow was positively related to enjoyment $(r=.62, p<.001)$, perceived learning $(r=.37, p<.001)$, motivation to critically reflect on advertising $(r=.35, p<.001)$ and motivation to interact with the learning materials $(r=.47, p<.001)$. Furthermore, enjoyment was positively related to perceived learning $(r=.66, p<.001)$, motivation to critically reflect on advertising $(r=.44, p<.001)$ and motivation to interact with the learning materials $(r=.69, p<.001)$. Perceived learning was also positively related to motivation to critically reflect on advertising $(r=.59, p<.001)$ and motivation to interact with the learning materials $(r=.64, p<.001)$. Finally, adolescents' motivation to critically reflect on advertising was positively related to motivation to interact with the learning materials $(r=.57, p<.001)$ and perceived dispositional advertising literacy $(r=.16, p=.023)$. Hence, perceived dispositional advertising literacy was only correlated with motivation to critically reflect on advertising. Table 1 presents the correlations between all the constructs included in this study. 
Table 1. Correlations.

\begin{tabular}{|c|c|c|c|c|c|c|}
\hline & 1. & 2. & 3. & 4. & 5. & 6. \\
\hline 1. Flow & 1 & $.62^{\star \star \star}$ & $.37 * \star \star$ & $.35^{\star \star \star}$ & $.47^{\star \star \star}$ & .08 \\
\hline 2. Enjoyment & & 1 & $.66 * \star \star$ & $.44^{* \star *}$ & $.69 * * *$ & .04 \\
\hline 3. Perceived learning & & & 1 & $.59 * \star \star$ & $.64 * \star \star$ & .07 \\
\hline $\begin{array}{l}\text { 4. Motivation to critically } \\
\text { reflect on advertising }\end{array}$ & & & & 1 & $.57 * \star \star$ & $.16^{*}$ \\
\hline $\begin{array}{l}\text { 5. Motivation to interact } \\
\text { with the learning materials }\end{array}$ & & & & & 1 & -.01 \\
\hline $\begin{array}{l}\text { 6. Perceived dispositional } \\
\text { advertising literacy }\end{array}$ & & & & & & 1 \\
\hline
\end{tabular}

Note: ${ }^{*} p<.05 ; * * p<.01 ; * \star * p<.001$

\section{The Effectiveness of an Advertising Literacy Intervention}

In the first part of the analyses, the effectiveness of an advertising literacy intervention (serious mini-game platform and informational booklet) was examined compared to the control condition (no intervention). First, an independent-samples $t$-test was performed to investigate whether an advertising literacy intervention enhanced adolescents' perceived dispositional advertising literacy compared to no intervention. The analysis showed that perceived dispositional advertising literacy was higher after exposure to an advertising literacy intervention ( $M=$ $3.02, S D=0.85)$ compared to no intervention $(M=2.64, S D=0.73 ; t(191)=-3.05, p=.003)$. This result confirms Hypothesis 1.

A mediation analysis (Hayes, 2018; PROCESS, model 4, 5000 bootstrap samples) was conducted to examine the impact of an advertising literacy intervention ( $0=$ no intervention, $1=$ advertising literacy intervention) on motivation to critically reflect on advertising via adolescents' perceived dispositional advertising literacy (as a mediator). The mediation analysis showed to be significant ( $B=.07, S E=.04,95 \% \mathrm{Cl}=[.0028, .1511]$, see Figure 5). An advertising literacy intervention (compared to no intervention) increased adolescents' perceived dispositional advertising literacy $(a=.35, S E=.12, t=2.87, p=.005)$, which subsequently positively affected their motivation to critically reflect on advertising $(b=.20, S E=.08, t=2.33, p=.021)$. This confirms Hypothesis 2 . The direct effect of advertising literacy intervention on motivation to critically reflect on advertising was marginally significant $\left(c^{\prime}=.28\right.$, $S E=.14, t=1.95, p=.053$ ).

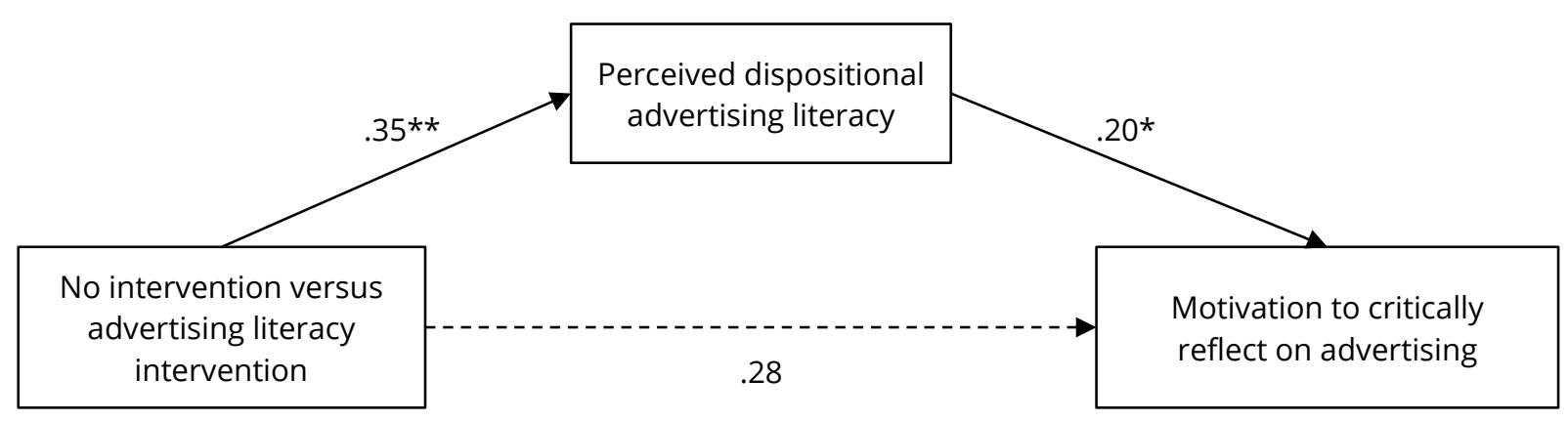

Figure 5. Indirect effect of advertising literacy intervention on motivation to critically reflect on advertising via perceived dispositional advertising literacy.

\section{Informational Booklet Versus Serious Mini-Game Platform}

We first investigated the main effects of advertising literacy intervention (informational booklet versus serious mini-game platform) on the different variables included in this study. We found a significant difference in flow. In particular, the adolescents experienced more flow while playing the serious mini-game platform compared to reading the informational booklet $(t(130)=-2.07, p=.040)$. In addition, we found a marginally significant difference in enjoyment $(t(130)=-1.90, p=.060)$. The adolescents experienced more enjoyment while playing the serious mini-game platform (compared to the booklet). There were no significant differences between the two interventions in perceived dispositional advertising literacy $(t(126)=1.42, p=.159)$, perceived learning $(t(129)=$ - 
$.25, p=.807)$, motivation to critically reflect on advertising $(t(126)=-.89, p=.374)$ and motivation to interact with the learning materials $(t(129)=-1.39, p=.169)$. Table 2 summarizes the means of the sample for the two experimental conditions.

Table 2. Summary of Results Under the Different Conditions of Advertising Literacy Intervention.

\begin{tabular}{lccc}
\hline & $\begin{array}{c}\text { Informational } \\
\text { booklet }\end{array}$ & $\begin{array}{c}\text { Serious mini- } \\
\text { game platform }\end{array}$ & $\begin{array}{c}\text { t-value } \\
\text { p-value }\end{array}$ \\
\hline Flow & $M=2.77$ & $M=3.15$ & $t(130)=-2.07$ \\
Enjoyment & $S D=1.01$ & $S D=1.09$ & $p=.040$ \\
Perceived dispositional & $M=3.30$ & $M=3.57$ & $t(130)=-1.90$ \\
advertising literacy & $S D=0.81$ & $S D=0.78$ & $p=.060$ \\
Perceived learning & $M=3.13$ & $M=2.92$ & $t(126)=1.42$ \\
& $S D=0.80$ & $S D=0.89$ & $p=.159$ \\
Motivation to critically & $M=2.85$ & $M=2.89$ & $t(129)=-.25$ \\
reflect on advertising & $S D=0.86$ & $S D=1.02$ & $p=.807$ \\
Motivation to interact with & $M=2.54$ & $M=2.70$ & $t(126)=-.89$ \\
the learning materials & $S D=0.98$ & $S D=1.01$ & $p=.374$ \\
\hline
\end{tabular}

In addition, four serial mediation analyses (Hayes, 2018; PROCESS, model 6, 5000 bootstrap samples) were conducted to examine how an advertising literacy intervention $(0=$ informational booklet, $1=$ serious mini-game platform) affects adolescents' motivational outcomes via their user experiences and learning outcomes (as mediators). In particular, we conducted a serial mediation analysis with flow, enjoyment and perceived learning as mediators and motivation to critically reflect on advertising as the dependent variable (1), and a serial mediation analysis with the same mediators but with motivation to interact with the learning materials as dependent variable (2). In addition, we also conducted a serial mediation analysis with flow, enjoyment and perceived dispositional advertising literacy as mediators and motivation to critically reflect on advertising as the dependent variable (3), and a serial mediation analysis with the same mediators but with motivation to interact with the learning materials as the dependent variable (4).

Motivation to critically reflect on advertising as a dependent variable. The first serial mediation with flow, enjoyment and perceived learning as mediators was significant $(B=.06, S E=.04,95 \% \mathrm{Cl}=[.0039, .1445]$, see Figure 6), confirming Hypothesis 7a. The adolescents experienced more flow while playing the serious mini-game platform (compared to reading the informational booklet) $(a=.38, S E=.19, t=2.05, p=.042$ ), which confirmed Hypothesis 3. Further, flow positively affected enjoyment $(d=.36, S E=.06, t=6.11, p<.001)$, confirming Hypothesis 4. This further resulted in a higher level of perceived learning among the adolescents $(b=.79, S E=.09, t=8.51, p$ $<.001)$. This result confirmed Hypothesis 5. Finally, perceived learning had a positive effect on motivation to critically reflect on advertising ( $e=.58, S E=.10, t=5.67, p<.001)$. There was no significant direct effect of advertising literacy intervention on motivation to critically reflect on advertising $\left(c^{\prime}=.12, S E=.15, t=.81, p=.420\right)$.

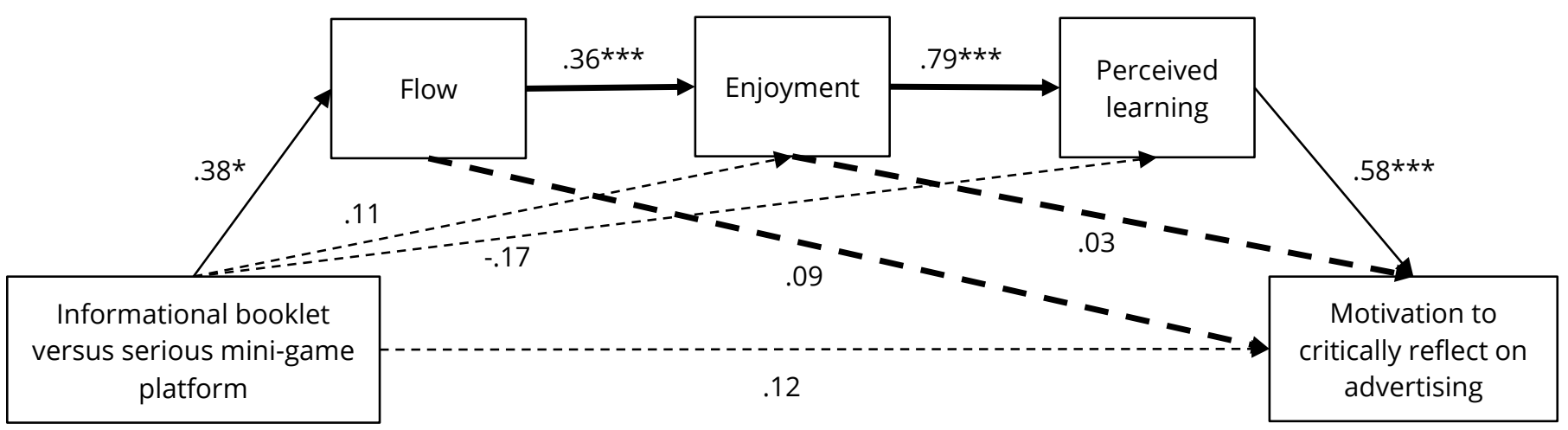

Figure 6. The indirect effect of advertising literacy intervention on motivation to critically reflect on advertising via flow, enjoyment and perceived learning. 
The serial mediation with flow, enjoyment and perceived dispositional advertising literacy as mediators was not significant $(B=.00, S E=.00,95 \% \mathrm{Cl}=[-.0042, .0104]$, see Figure 7$)$, as there was no significant effect of enjoyment on perceived dispositional advertising literacy $(B=.07, S E=.11, t=.60, p=.551)$ and of perceived dispositional advertising literacy on motivation to critically reflect on advertising $(B=.14, S E=.10, t=1.48, p=.142)$. Therefore, Hypotheses 6 and $8 \mathrm{a}$ are rejected. The analysis did show a significant indirect effect of intervention on motivation to critically reflect on advertising via only flow and enjoyment as mediators $(B=.07, S E=.04,95 \% \mathrm{Cl}=[.0013$, $.1565])$, as there was a significant effect of enjoyment on motivation to critically reflect on advertising $(B=.47, S E$ $=.12, t=4.05, p<.001)$.

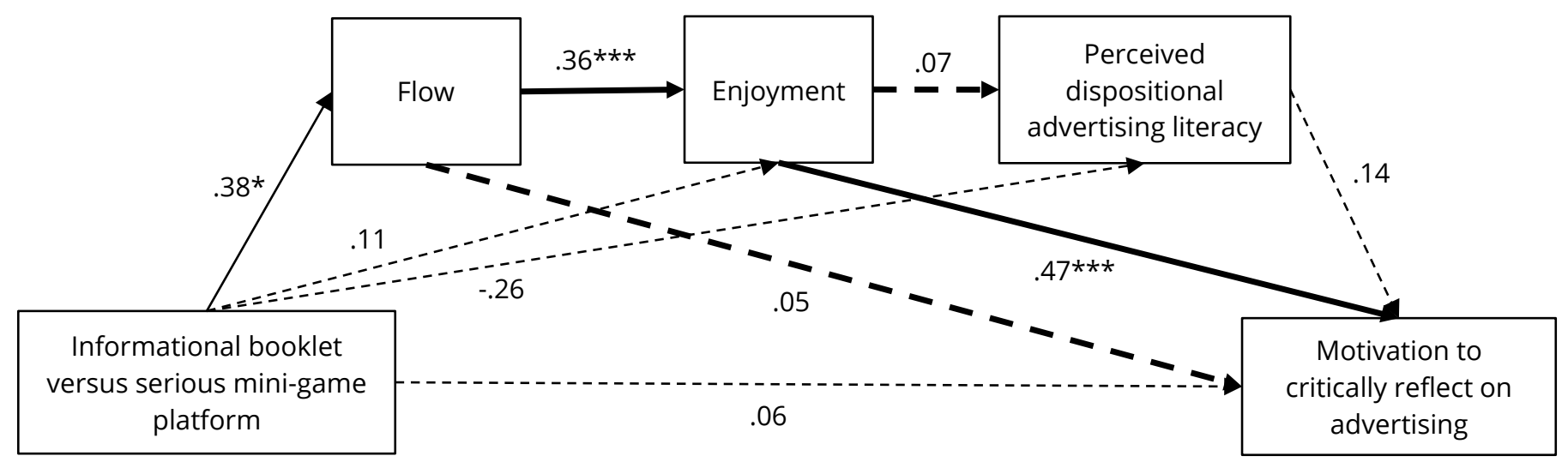

Figure 7. The indirect effect of advertising literacy intervention on motivation to critically reflect on advertising via flow, enjoyment and perceived dispositional advertising literacy.

Motivation to interact with the learning materials as a dependent variable. The serial mediation with flow, enjoyment and perceived learning as mediators showed to be significant $(B=.04, S E=.02,95 \% \mathrm{Cl}=[.0044, .0984]$, see Figure 8$)$, confirming Hypothesis $7 \mathrm{~b}$. Adolescents reported a higher level of flow while playing the serious minigame platform $(a=.41, S E=.18, t=2.25, p=.026)$, which positively affected enjoyment $(d=.37, S E=.06, t=6.36, p$ $<.001)$ and further perceived learning $(e=.80, S E=.09, t=8.69, p<.001)$. Furthermore, perceived learning had a positive effect on motivation to interact with the learning materials $(b=.32, S E=.08, t=3.93, p<.001)$. The serial mediation with only flow and enjoyment as mediators was also significant $(B=.07, S E=.04,95 \% \mathrm{Cl}=[.0095, .1580])$, as the effect of enjoyment on motivation to interact with the learning materials was significant $(B=.48, S E=.11, t$ $=4.44, p<.001)$. The direct effect of advertising literacy intervention on motivation to interact with the learning materials was not significant $\left(c^{\prime}=.08, S E=.12, t=.64, p=.521\right)$.

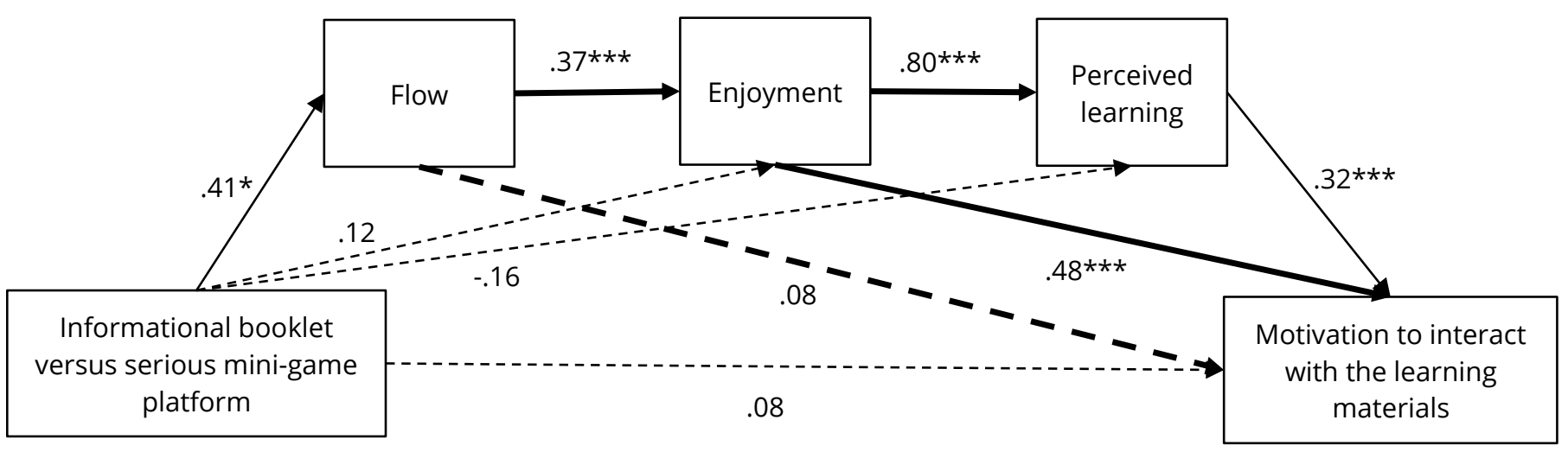

Figure 8. The indirect effect of advertising literacy intervention on motivation to interact with the learning materials via flow, enjoyment and perceived learning. 
The serial mediation with flow, enjoyment and perceived dispositional advertising literacy as mediators on the effect of intervention on motivation to interact with the learning materials was not significant $(B=.00, S E=.00$, $95 \% \mathrm{Cl}=[-.0028, .0032]$, see Figure 9$)$, as enjoyment had no significant effect on perceived dispositional advertising literacy $(B=.07, S E=.11, t=.60, p=.551)$ and perceived dispositional advertising literacy had no effect on motivation to interact with the learning materials $(B=.02, S E=.07, t=.26, p=.794)$. Hypothesis $8 \mathrm{~b}$ is therefore rejected. The serial mediation with only flow and enjoyment as mediators was significant $(B=.10, S E=.05,95 \% \mathrm{Cl}$ $=[.0034, .2092])$.

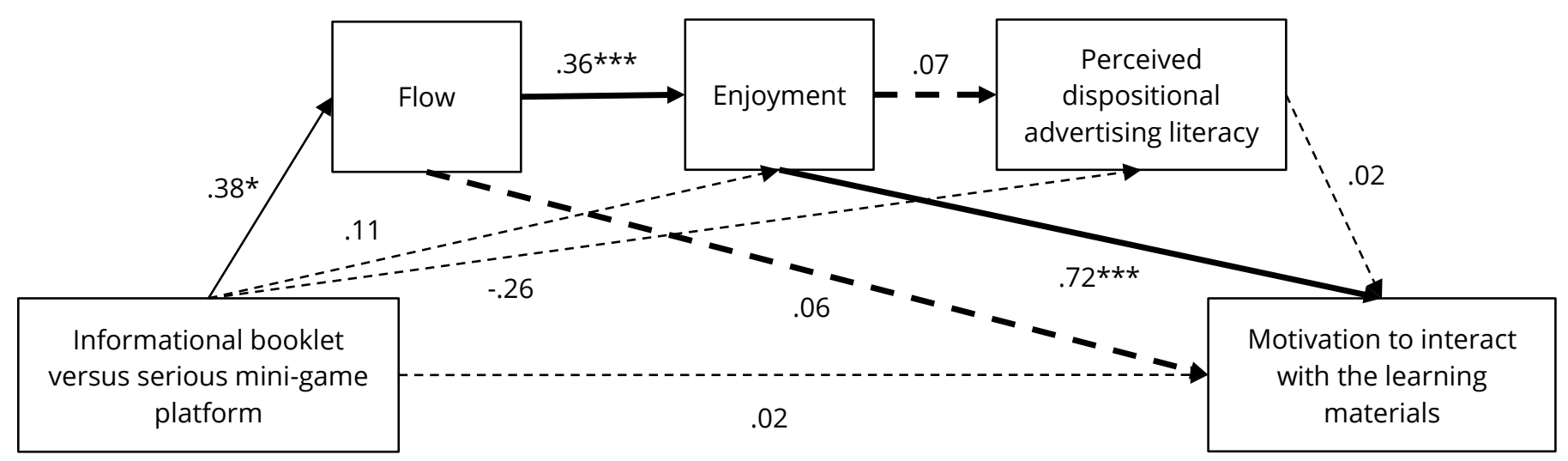

Figure 9. The indirect effect of advertising literacy intervention on motivation to interact with the learning materials via flow, enjoyment and perceived dispositional advertising literacy.

\section{Discussion and Conclusion}

Although it is assumed that adolescents are less susceptible to advertising than children, adolescents' cognitive and information processing skills are still evolving (Boush et al., 1994; Friestad \& Wright, 1994) and their advertising literacy is not yet fully developed, especially when it comes to embedded advertising (Vanwesenbeeck et al., 2016; Verhellen et al., 2014; Zarouali et al., 2018). This study therefore examined the impact of advertising literacy interventions on adolescents' learning and motivational outcomes. In addition, it was tested whether a DGBL approach (using serious mini-games) is successful in increasing adolescents' user experiences, learning outcomes and motivational outcomes (by comparing it with a traditional learning approach).

First, the current study showed that an advertising literacy intervention (compared to no intervention) is successful in enhancing adolescents' (ten to sixteen years) confidence in their knowledge about different advertising tactics, which further increases their motivation to critically reflect on advertising. These results are in agreement with previous studies that showed that advertising literacy interventions (traditional classroom lessons, instructional films, and serious games) are effective tools for enhancing minors' (mainly children's) advertising literacy and their skeptical attitude toward advertising (e.g. An et al., 2014; Brucks et al., 1988; De Jans, Hudders, et al., 2017; Donohue et al., 1983; Hudders et al., 2016; Nelson, 2016).

Furthermore, this study examined whether a DGBL approach (in the form of a serious mini-game platform) is more successful in increasing adolescents' user experiences and learning and motivational outcomes than a traditional learning approach. The results of the study indicated that adolescents experienced a greater state of flow when they were playing the serious mini-game platform than when they were reading the booklet. This can be explained by flow theory (Csikszentmihalyi, 1990), as the serious mini-games were especially developed to induce a balanced relationship between the challenges of the games and the skills of the players that are needed to meet those challenges. The impact of the DGBL approach on the experience of flow may also be due to the interactive and immersive characteristics of mini-games and is in line with previous studies on DGBL that have shown that serious games are effective in enhancing the experience of flow among minors (Admiraal et al., 2011; Hamari et al., 2016; Hung, Sun, \& Yu, 2015; Hwang et al., 2012). As hypothesized, the enhanced experience of flow among adolescents subsequently positively affected enjoyment of the experience (Admiraal et al., 2011; Barzilai \& Blau, 2014; Hamari et al., 2016; Kiili, 2005). 
It was also investigated whether and how the advertising literacy serious mini-game platform (compared to the booklet) affected learning outcomes among adolescents. It can be concluded that the serious mini-game platform did not directly affect adolescents' learning outcomes, but only indirectly through underlying mechanisms (user experiences). Hence, these results suggest that the impact of the serious mini-game platform on learning outcomes should not be overestimated in the short run and after a single exposure. These results are in line with previous research that found that a DGBL approach does not necessarily induce more effective learning among adolescents (in the short run) compared to a traditional learning approach (e.g. Annetta et al., 2009); whereas other studies did find more learning outcomes after exposure to a gaming approach compared to a traditional approach (e.g. Papastergiou, 2009). These results may be explained because the participants in the experiment were only exposed to the serious mini-game platform once for 20 minutes. Hence, the experiment consisted of a single play experience for the adolescents, whereas the serious mini-games would probably be played multiple times in real life. In addition, such a gaming platform is intended to be part of a holistic learning approach to teach adolescents about a specific learning subject (advertising in this case). For example, these serious mini-games could be integrated into the curriculum to support a teaching package in class. Thus, it is expected that the serious mini-game platform would have a greater impact on learning outcomes in the long run when it is integrated into a holistic learning approach.

Furthermore, the significant indirect effect of the advertising literacy intervention on perceived learning via flow and enjoyment provides evidence for the assumption that flow, enjoyment, and perceived learning are strongly correlated in the context of DGBL and that the enhanced, consecutive experiences of flow and enjoyment result in adolescents perceiving that they gained more knowledge about the topic (Barzilai \& Blau, 2014; Hamari et al., 2016).

Finally, the results of this study also show that the increased experiences of flow, enjoyment and perceived learning, when playing a serious mini-game platform, increase adolescents' motivational outcomes. Hence, perceived learning is especially considered an important construct in DGBL, as perceived learning about advertising leads to adolescents being more motivated to critically reflect on advertising and to interact with the learning materials again. In particular, after playing a serious mini-game platform, adolescents will be more intrinsically motivated to use their knowledge and interact longer and more frequently with the learning materials, which may lead to more actual learning outcomes in the long run.

\section{Implications}

Practical implications. This study addresses some important practical implications. It was examined whether adolescents' perceived knowledge about advertising could be enhanced by implementing an advertising literacy intervention. In particular, the current study investigated the effectiveness of a serious mini-game platform by comparing it with a traditional learning approach (an informational booklet). The results of the current study show that adolescents experienced more flow and enjoyment while playing the serious mini-game platform compared to reading the booklet. Furthermore, these enhanced user experiences increased adolescents' (perceived) learning outcomes and, subsequently, their motivational outcomes. Hence, the results of this study suggest that serious mini-games (or a serious mini-game platform) can be useful tools for educational purposes. However, the learning outcomes of the game platform are rather limited compared to the informational booklet, as there are only indirect effects on learning and motivational outcomes. Therefore, we suggest that it is important that these games are part of a holistic learning approach. For example, the games can be integrated into the curriculum to support pedagogical packages by including them as an introduction or closing of a didactic package. Mini-games do not require much time investment from players, so they can easily fit within a class period. The game platform can also be used as a homework assignment for the students to introduce them to the pedagogical package before the lessons or as a repetition at the end of the teaching package. As these games are fun and entertaining, adolescents will be intrinsically motivated to interact with the learning platform again and learn more about the topic.

In addition, the results of the current study show that the serious mini-game platform increases flow and, subsequently, enjoyment among adolescents. Thus, this indicates that serious mini-games are capable of inducing a balanced interplay between challenges and the players' skills. This interplay between challenges and skills in combination with the interactive and immersive characteristics of the serious mini-games ensures a feeling of 
enjoyment among the adolescents. Additionally, these enhanced experiences of flow and further enjoyment cause adolescents to be more intrinsically motivated to interact with the learning materials again. This is an important outcome for a learning platform, as this may enhance actual learning and knowledge acquisition in the long run. Hence, when adolescents are introduced to the learning platform in class, they might be motivated to interact with the serious mini-game platform again in their leisure time, which may enhance their actual learning.

Finally, a serious mini-game platform is especially fun and entertaining, as it consists of several different minigames that can be played separately. Hence, when players are tired of playing a particular mini-game, they can switch to another mini-game within the same gaming platform and still be actively involved with the same learning topic, albeit a different aspect of that learning topic. In contrast, when players are bored playing a conventional serious game (which is only one large game), then they will stop playing that game and will therefore no longer be actively involved with the learning materials.

Theoretical implications. The current study contributes to the existing literature by showing that a serious minigame platform is a useful tool to enhance adolescents' user experiences, which can further facilitate learning and subsequently motivational outcomes. Although previous research has proven the effectiveness of conventional serious games among minors (Backlund \& Hendrix, 2013; Boyle et al., 2016; Connolly, Boyle, MacArthur, Hainey, \& Boyle, 2012), the effectiveness of serious mini-games has rarely been investigated. Hence, the current study provides evidence for the effectiveness of serious mini-games and suggests that they can be promising tools for educational purposes, for example, to raise awareness of a societal issue. This platform focuses on different aspects of a learning topic in an entertaining way, thus motivating players and inducing a positive attitude toward learning and behavioral change. Whereas conventional serious games take multiple hours to master, mini-games can be played within a few minutes; thus, players are easily motivated to play these games repeatedly, which exposes them to the games' learning goals several times (Juul, 2010; Trefry, 2010). As some authors questioned the educational value of mini-games because they are believed to be shallow and small (Frazer et al., 2007; Prensky, 2005), a serious mini-game platform was introduced as a solution (Frazer et al., 2007; Smith \& Sanchez, 2010). This platform, consisting of different mini-games, explores a learning topic from different angles by focusing each mini-game on a specific learning goal that contributes to a didactic unit (Illanas et al., 2008).

The current study shows that a serious mini-game platform may not directly affect adolescents' (perceived) learning outcomes. Hence, adolescents do not perceive themselves to be more knowledgeable after exposure to a serious mini-game platform compared to a traditional learning approach. However, the serious mini-game platform (compared to the traditional learning approach) did enhance adolescents' experience of flow, which further increased their enjoyment in interacting with the learning approach. The user experiences of flow and enjoyment subsequently have a positive effect on the (perceived) learning outcomes among the adolescents. This shows that user experiences may be considered especially crucial in the effectiveness of a serious mini-game platform. In addition, although it cannot be concluded from the current study that the serious mini-game platform enhanced adolescents' actual learning about advertising, it is important to note that the serious mini-game platform did enhance perceived learning about advertising (through the experiences of flow and enjoyment), which also further increased adolescents' motivation to critically reflect on advertising and their motivation to interact with the learning materials. These motivational outcomes should not be underestimated as it may enhance actual knowledge acquisition in the long run.

\section{Limitations and Suggestions for Future research}

The current study has some limitations that translate into suggestions for future research. The main limitation of this study is that the scales for learning outcomes are based on self-reported data and measure how adolescents perceive their learning outcomes after playing the mini-games or reading the informational booklet, instead of measuring their actual learning outcomes and knowledge acquisition on advertising (literacy). Hence, it is possible that the adolescents gave socially desirable answers. However, most scales that measure dispositional advertising literacy use self-reported items or reflective questions. In addition, further research could measure adolescents' situational advertising literacy (i.e. advertising literacy after exposure to a specific advertising attempt) after exposure to the advertising literacy interventions. Furthermore, future research could examine adolescents' actual advertising literacy and learning outcomes after exposure to either the game platform or the informational booklet by quizzing the adolescents about advertising afterwards and using their scores as dependent variables. 
Another limitation is that the learning outcomes (such as perceived dispositional advertising literacy) were not also measured before exposure to the stimuli; however, this would have triggered effects and would have affected the measures after exposure to the stimuli material.

In addition, the impact of the serious mini-game platform on the learning and motivational outcomes is quite limited, as the game platform only indirectly affected these outcomes through increased levels of flow and enjoyment among the adolescents. This might be because the adolescents only had one isolated interaction with the learning materials. Future research could examine the impact of the serious mini-game platform on adolescents' learning and motivational outcomes when it is integrated into a holistic learning approach.

Furthermore, with our study, we cannot conclude whether a serious mini-game platform is more effective than a conventional serious game when it comes to user experiences and learning and motivational outcomes, as we only compared the serious mini-game platform to no intervention and a traditional learning approach (i.e. informational booklet). Future research could examine and compare adolescents' user experiences, and learning and motivational outcomes for a conventional serious game and a serious mini-game platform to see which form of DGBL is most effective.

Finally, the study only examined the short-term effects of the serious mini-game platform. Of course, to provide any real educational value, advertising literacy interventions should also be effective in the long run. Future research should therefore examine the long-term or delayed effects of a serious mini-game platform by examining the effectiveness after a few days, weeks or even months.

\section{References}

Adams, B., Schellens, T., \& Valcke, M. (2017). Promoting adolescents' moral advertising literacy in secondary education. Comunicar: Media Education Research Journal, 25(52), 93-103. https://doi.org/10.3916/C52-2017-09

Admiraal, W., Huizenga, J., Akkerman, S., \& Ten Dam, G. (2011). The concept of flow in collaborative game-based learning. Computers in Human Behavior, 27, 1185-1194. https://doi.org/10.1016/j.chb.2010.12.013

An, S., Jin, H. S., \& Park, E. H. (2014). Children's advertising literacy for advergames: Perception of the game as advertising. Journal of Advertising, 43, 63-72. https://doi.org/10.1080/00913367.2013.795123

Annetta, L. A., Minogue, J., Holmes, S. Y., \& Cheng, M.-T. (2009). Investigating the impact of video games on high school students' engagement and learning about genetics. Computers \& Education, 53, 74-85.

https://doi.org/10.1016/j.compedu.2008.12.020

Austin, E. W., \& Johnson, K. K. (1997). Immediate and delayed effects of media literacy training on third grader's decision making for alcohol. Health Communication, 9, 323-349. https://doi.org/10.1207/s15327027hc0904_3

Backlund, P., \& Hendrix, M. (2013). Educational games-are they worth the effort? A literature survey of the effectiveness of serious games. In 2013 5th International Conference on Games and Virtual Worlds for Serious Applications (VS-GAMES) (pp. 1-8). Retrieved from https://doi.org/10.1109/VS-GAMES.2013.6624226

Baker, M. J., \& George, L. M. (2010). The role of television in household debt: Evidence from the 1950's. The BE Journal of Economic Analysis \& Policy, 10(1), article 41. https://doi.org/10.2202/1935-1682.2393

Bandura, A. (1986). Social foundations of thought and action: A social cognitive theory. Englewood Cliffs, NJ, US: Prentice-Hall, Inc.

Barzilai, S., \& Blau, I. (2014). Scaffolding game-based learning: Impact on learning achievements, perceived learning, and game experiences. Computers \& Education, 70, 65-79.

https://doi.org/10.1016/j.compedu.2013.08.003 
Bellotti, F., Kapralos, B., Lee, K., Moreno-Ger, P., \& Berta, R. (2013). Assessment in and of serious games: An overview. Advances in Human-Computer Interaction. Advanced online publication.

https://doi.org/10.1155/2013/136864

Boush, D. M., Friestad, M., \& Rose, G. M. (1994). Adolescent skepticism toward TV advertising and knowledge of advertiser tactics. Journal of Consumer Research, 21, 165-175. https://doi.org/10.1086/209390

Boyle, E. A., Hainey, T., Connolly, T. M., Gray, G., Earp, J., Ott, M., ... Pereira, J. (2016). An update to the systematic literature review of empirical evidence of the impacts and outcomes of computer games and serious games. Computers \& Education, 94, 178-192. https://doi.org/10.1016/j.compedu.2015.11.003

Brom, C., Buchtová, M., Šisler, V., Děchtěrenko, F., Palme, R., \& Glenk, L. M. (2014). Flow, social interaction anxiety and salivary cortisol responses in serious games: A quasi-experimental study. Computers \& Education, 79, 69-100. https://doi.org/10.1016/j.compedu.2014.07.001

Brom, C., Preuss, M., \& Klement, D. (2011). Are educational computer micro-games engaging and effective for knowledge acquisition at high-schools? A quasi-experimental study. Computers \& Education, 57, 1971-1988. https://doi.org/10.1016/j.compedu.2011.04.007

Brucks, M., Armstrong, G. M., \& Goldberg, M. E. (1988). Children's use of cognitive defenses against television advertising: A cognitive response approach. Journal of Consumer Research, 14, 471-482.

https://doi.org/10.1086/209129

Caspi, A., \& Blau, I. (2008). Social presence in online discussion groups: Testing three conceptions and their relations to perceived learning. Social Psychology of Education, 11, 323-346. https://doi.org/10.1007/s11218-0089054-2

Connolly, T. M., Boyle, E. A., MacArthur, E., Hainey, T., \& Boyle, J. M. (2012). A systematic literature review of empirical evidence on computer games and serious games. Computers \& Education, 59, 661-686.

https://doi.org/10.1016/j.compedu.2012.03.004

Csikszentmihalyi, M. (1990). Flow: The psychology of optimal experience. New York: Harper \& Row.

De Jans, S., Hudders, L., \& Cauberghe, V. (2017). Advertising literacy training: The immediate versus delayed effects on children's responses to product placement. European Journal of Marketing, 51, 2156-2174.

https://doi.org/10.1108/EJM-08-2016-0472

De Jans, S., Hudders, L., \& Cauberghe, V. (2018). Adolescents' self-reported level of dispositional advertising literacy: How do adolescents resist advertising in the current commercial media environment? Young Consumers, 19, 402-420. http://dx.doi.org/10.1108/YC-02-2018-00782

De Jans, S., Van Geit, K., Cauberghe, V., Hudders, L., \& De Veirman, M. (2017). Using games to raise awareness: How to co-design serious mini-games? Computers \& Education, 110, 77-87.

https://doi.org/10.1016/j.compedu.2017.03.009

Donohue, T. R., Henke, L. L., \& Meyer, T. P. (1983). Learning about television commercials: The impact of instructional units on children's perceptions of motive and intent. Journal of Broadcasting \& Electronic Media, 27, 251-261. https://doi.org/10.1080/08838158309386490

Eagle, L. (2007). Commercial media literacy: What does it do, to whom-and does it matter? Journal of Advertising, 36(2), 101-110. https://doi.org/10.2753/JOA0091-3367360207

Fransen, M. L., Verlegh, P. W. J., Kirmani, A., \& Smit, E. G. (2015). A typology of consumer strategies for resisting advertising, and a review of mechanisms for countering them. International Journal of Advertising, 34, 6-16. 
Frazer, A., Argles, D., \& Wills, G. (2007). Is less actually more? The usefulness of educational mini-games. In Seventh IEEE International Conference on Advanced Learning Technologies (ICALT 2007) (pp. 533-537). Retrieved from https://doi.org/10.1109/ICALT.2007.173

Friestad, M., \& Wright, P. (1994). The persuasion knowledge model: How people cope with persuasion attempts. Journal of Consumer Research, 21, 1-31. https://doi.org/10.1086/209380

Hamari, J., Shernoff, D. J., Rowe, E., Coller, B., Asbell-Clarke, J., \& Edwards, T. (2016). Challenging games help students learn: An empirical study on engagement, flow and immersion in game-based learning. Computers in Human Behavior, 54, 170-179. https://doi.org/10.1016/j.chb.2015.07.045

Hayes, A. F. (2018). Introduction to mediation, moderation, and conditional process analysis: A regression-based approach. New York: Guilford Publications.

Hoffman, D. L., \& Novak, T. P. (2009). Flow online: Lessons learned and future prospects. Journal of Interactive Marketing, 23, 23-34. https://doi.org/10.1016/j.intmar.2008.10.003

Hou, H.-T. (2015). Integrating cluster and sequential analysis to explore learners' flow and behavioral patterns in a simulation game with situated-learning context for science courses: A video-based process exploration. Computers in Human Behavior, 48, 424-435. https://doi.org/10.1016/j.chb.2015.02.010

Hudders, L., Cauberghe, V., \& Panic, K. (2016). How advertising literacy training affect children's responses to television commercials versus advergames. International Journal of Advertising, 35, 909-931.

https://doi.org/10.1080/02650487.2015.1090045

Hudders, L., Pauw, P. D., Cauberghe, V., Panic, K., Zarouali, B., \& Rozendaal, E. (2017). Shedding new light on how advertising literacy can affect children's processing of embedded advertising formats: A future research agenda. Journal of Advertising, 46, 333-349. https://doi.org/10.1080/00913367.2016.1269303

Hung, C.-Y., Sun, J. C.-Y., \& Yu, P.-T. (2015). The benefits of a challenge: Student motivation and flow experience in tablet-PC-game-based learning. Interactive Learning Environments, 23, 172-190.

https://doi.org/10.1080/10494820.2014.997248

Hwang, G.-J., Wu, P.-H., \& Chen, C.-C. (2012). An online game approach for improving students' learning performance in web-based problem-solving activities. Computers \& Education, 59, 1246-1256.

https://doi.org/10.1016/j.compedu.2012.05.009

Illanas, A. I., Gallego, F., Satorre, R., \& Llorens, F. (2008). Conceptual mini-games for learning. Paper presented at the IATED International Technology, Education and Development Conference, Valencia, Spain. Retrieved from https://rua.ua.es/dspace/bitstream/10045/8495/1/illanas08conceptual.pdf

John, D. R. (1999). Consumer socialization of children: A retrospective look at twenty-five years of research. Journal of Consumer Research, 26, 183-213. https://doi.org/10.1086/209559

Jonker, V., Wijers, M., \& Van Galen, F. (2009). The motivational power of mini-games for the learning of mathematics. In Proceedings of the 3rd European Conference on Gamebased Learning (ECGBL) (pp. 202-210). Reading, UK: Academic Conferences Ltd.

Juul, J. (2010). A casual revolution: Reinventing video games and their players. Cambridge, MA: MIT press.

Ke, F., \& Grabowski, B. (2007). Gameplaying for maths learning: Cooperative or not? British Journal of Educational Technology, 38, 249-259. https://doi.org/10.1111/j.1467-8535.2006.00593.x

Kiili, K. (2005). Content creation challenges and flow experience in educational games: The IT-Emperor case. The Internet and Higher Education, 8, 183-198. https://doi.org/10.1016/j.iheduc.2005.06.001 
Kiili, K. (2005). Digital game-based learning: Towards an experiential gaming model. The Internet and Higher Education, 8, 13-24. https://doi.org/10.1016/j.iheduc.2004.12.001

Lapierre, M. A., Fleming-Milici, F., Rozendaal, E., McAlister, A. R., \& Castonguay, J. (2017). The effect of advertising on children and adolescents. Pediatrics, 140(Suppl. 2), S152-S156. https://doi.org/10.1542/peds.2016-1758V

Lapowsky, I. (2014, March 3). Why teens are the most elusive and valuable customers in tech. Inc. Retrieved from https://www.inc.com/issie-lapowsky/inside-massive-tech-land-grab-teenagers.html

Marfisi-Schottman, I., George, S., \& Tarpin-Bernard, F. (2010). Tools and methods for efficiently designing serious games. In Proceedings of the 4th European Conference on Games Based Learning (ECGBL) (pp. 226-234). Reading, UK: Academic Conferences Ltd.

Nairn, A. (2014). Advertising and child well-being. In A. Ben-Arieh, F. Casas, I. FrØnes, \& J.E. Korbin (Eds.), Handbook of child well-being (pp. 2031-2055). London: Springer.

Nelson, M. R. (2016). Developing persuasion knowledge by teaching advertising literacy in primary school. Journal of Advertising, 45, 169-182. https://doi.org/10.1080/00913367.2015.1107871

Ofcom. (2017, November 29). Children and parents: media use and attitudes report 2017. Retrieved from https://www.ofcom.org.uk/research-and-data/media-literacy-research/childrens/children-parents-2017

Papastergiou, M. (2009). Digital game-based learning in high school computer science education: Impact on educational effectiveness and student motivation. Computers \& Education, 52, 1-12.

https://doi.org/10.1016/j.compedu.2008.06.004

Pekrun, R., Goetz, T., Frenzel, A. C., Barchfeld, P., \& Perry, R. P. (2011). Measuring emotions in students' learning and performance: The Achievement Emotions Questionnaire (AEQ). Contemporary Educational Psychology, 36, 3648. https://doi.org/10.1016/j.cedpsych.2010.10.002

Pekrun, R., Goetz, T., Titz, W., \& Perry, R. P. (2002). Academic emotions in students' self-regulated learning and achievement: A program of qualitative and quantitative research. Educational Psychologist, 37, 91-105.

https://doi.org/10.1207/S15326985EP3702_4

Pine, B. J., Peppers, D., \& Rogers, M. (2009). Do you want to keep your customers forever? Brighton, MA, US: Harvard Business Press.

Prensky, M. (2003). Digital game-based learning. Computers in Entertainment (CIE), 1, 21-21. https://doi.org/10.1145/950566.950596

Prensky, M. (2005). In educational games, complexity matters: Mini-games are trivial-but "'complex"'games are not. Educational Technology, 45(4), 22-28. Retrieved from http://www.jstor.org/stable/44429218

Prensky, M. (2008). Students as designers and creators of educational computer games: Who else? British Journal of Educational Technology, 39, 1004-1019. https://doi.org/10.1111/j.1467-8535.2008.00823_2.x

Qian, M., \& Clark, K. R. (2016). Game-based Learning and 21st century skills: A review of recent research. Computers in Human Behavior, 63, 50-58. https://doi.org/10.1016/j.chb.2016.05.023

Refiana, L., Mizerski, D., \& Murphy, J. (2005). Measuring the state of flow in playing online games. In Proceedings of ANZMAC 2005 Conference, Marketing Research and Research Methodologies (quantitative) (pp. 108-113).

Ritterfeld, U., Cody, M., \& Vorderer, P. (2009). Serious games: Mechanisms and effects. New York: Routledge. 
Ritterfeld, U., \& Weber, R. (2006). Video games for entertainment and education. In P. Vorderer \& J. Bryant (Eds.), Playing video games: Motives, responses, and consequences (pp. 399-413). Mahwah, NJ, US: Lawrence Erlbaum Associates Publishers.

Roberts, D. F., Christenson, P., Gibson, W. A., Mooser, L., \& Goldberg, M. E. (1980). Developing discriminating consumers. Journal of Communication, 30(3), 94-105. https://doi.org/10.1111/j.1460-2466.1980.tb01996.x

Rosas, R., Nussbaum, M., Cumsille, P., Marianov, V., Correa, M., Flores, P., ... López, V. (2003). Beyond Nintendo: Design and assessment of educational video games for first and second grade students. Computers \& Education, 40, 71-94. https://doi.org/10.1016/S0360-1315(02)00099-4

Rozendaal, E., Lapierre, M. A., Van Reijmersdal, E. A., \& Buijzen, M. (2011). Reconsidering advertising literacy as a defense against advertising effects. Media Psychology, 14, 333-354.

https://doi.org/10.1080/15213269.2011.620540

Rozendaal, E., Opree, S. J., \& Buijzen, M. (2016). Development and validation of a survey instrument to measure children's advertising literacy. Media Psychology, 19, 72-100. https://doi.org/10.1080/15213269.2014.885843

Scaife, M., Rogers, Y., Aldrich, F., \& Davies, M. (1997). Designing for or designing with? Informant design for interactive learning environments. In Proceedings of the ACM SIGCHI Conference on Human factors in computing systems (pp. 343-350). New York, NY, US: ACM.

Smith, P. A., \& Sanchez, A. (2010). Mini-games with major impacts. In J. Cannon-Bowers \& C. Bowers (Eds.), Serious Game Design and Development: Technologies for Training and Learning (pp. 1-12). Hershey, PA: IGI Global. https://doi.org/10.4018/978-1-61520-739-8.ch001

Statista. (2019a). Global kids ad spend 2019. Retrieved from https://www.statista.com/statistics/750865/kidsadvertising-spending-worldwide/

Statista. (2019b). Serious games revenues worldwide 2023. Retrieved from https://www.statista.com/statistics/733616/game-based-learning-industry-revenue-world/

Sung, H.-Y., \& Hwang, G.-J. (2013). A collaborative game-based learning approach to improving students' learning performance in science courses. Computers \& Education, 63, 43-51.

https://doi.org/10.1016/j.compedu.2012.11.019

Susi, T., Johannesson, M., \& Backlund, P. (2007). Serious games: An overview. Skövde: Institutionen för kommunikation och information.

Trefry, G. (2010). Casual game design: Designing play for the gamer in all of us. Burlington, MA, US: Elsevier Inc.

Vanwesenbeeck, I., Wolf, D., Lambrecht, I., Hudders, L., Cauberghe, V., Adams, B., ... Lissens, S. (2016). Minors' advertising literacy in relation to new advertising formats: identification and assessment of the risks. AdLit SBO.

Verhellen, Y., Oates, C., De Pelsmacker, P., \& Dens, N. (2014). Children's responses to traditional versus hybrid advertising formats: The moderating role of persuasion knowledge. Journal of Consumer Policy, 37, 235-255. https://doi.org/10.1007/s10603-014-9257-1

Vorderer, P., Klimmt, C., \& Ritterfeld, U. (2004). Enjoyment: At the heart of media entertainment. Communication Theory, 14, 388-408. https://doi.org/10.1111/j.1468-2885.2004.tb00321.x

Wollslager, M. E. (2009). Children's awareness of online advertising on Neopets: The effect of media literacy training on recall. SIMILE: Studies In Media \& Information Literacy Education, 9(2), 31-53. 
Wouters, P., Van Nimwegen, C., Van Oostendorp, H., \& Van Der Spek, E. D. (2013). A meta-analysis of the cognitive and motivational effects of serious games. Journal of Educational Psychology, 105, 249-265.

https://doi.org/10.1037/a0031311

Zarouali, B., Verdoodt, V., Walrave, M., Poels, K., Ponnet, K., \& Lievens, E. (2018). Adolescents' persuasion skills and privacy protection strategies in the context of targeted advertising on social networking sites: Implications for regulation. Paper presented at 17th International Conference on Research in Advertising (ICORIA), Valencia, Spain.

\author{
Correspondence to: \\ Steffi De Jans \\ Doctoral student, Department of Communication Sciences \\ Ghent University \\ Korte Meer 7-9-11 \\ 9000 Gent \\ Belgium \\ Email: Steffi.DeJans(at)UGent.be
}

Editorial record: First submission received on October 8, 2018. Revisions received on February 5, 2019, March 21, 2019, and May 9, 2019. Accepted for publication on May 9, 2019.

The article is part of the Special Issue "Digital Advertising and Consumer Empowerment" guest edited by Liselot Hudders (Ghent University, Ghent, Belgium), Karolien Poels (University of Antwerp, Antwerp, Belgium), and Eva van Reijmersdal (University of Amsterdam, Amsterdam, The Netherlands).

\title{
About Authors
}

Steffi De Jans is a doctoral student at the department of communication sciences at Ghent University (Belgium). She graduated in 2015 as a Master in Communication Management at the Department Communication Sciences at Ghent University. Her research interest lays on minors' advertising literacy for embedded advertising formats and how this advertising literacy can be improved.

Liselot Hudders is an assistant professor at the department of communication sciences at Ghent University and a postdoctoral fellow of the FWO at the marketing department. Her research interests include persuasive communication, consumer behavior and advertising literacy. Her research focus lays on how consumption affects an individual's well-being and how children and youngsters cope with (new) advertising techniques.

Laura Herrewijn is a postdoctoral research and assistant processor in digital marketing at the department of Communication Sciences at Ghent University (Belgium). Her research focuses on virtual environments (such as those represented in digital games, virtual and augmented reality apps) and their potential for the integration of persuasive communication (e.g. advertising, educational content), along with consumer behavior (e.g. in-app purchases).

Klara van Geit is a language teacher who teaches Dutch to foreign students at Leerpunt Aalst. In 2014 she worked as a doctoral researcher on a science communication project which focused on advertising literacy among adolescents. In 2011 she graduated as a Master of Arts at Ghent University.

Veroline Cauberghe is associate professor in Communication Management at the Ghent University (Belgium). Her research interest lays on advertising effectiveness and social marketing. In the past she did research related to advertising knowledge among minors, the persuasive impact of communication strategies (e.g., two-sided messages) and crisis communication. 